\title{
О ПОДХОДЕ К УПРАВЛЕНИЮ ТЕХНОЛОГИЧЕСКОЙ ЭФФЕКТИВНОСТЬЮ СОЗДАВАЕМЫХ ТЕХНИЧЕСКИХ ОБЪЕКТОВ
}

\author{
Воинова С. А., канд. техн. наук, доцент, \\ Одесская национальная академия пищевых технологий
}

Аннотация: Рассмотрены возможные подходы к управлению технологической эффективностью создаваемых технических объектов. Показана целесообразность использования широкого аспекта решения указанной задачи. Работа по созданию системы управления представлена в виде трех последовательных этапов.

Annotation: Possible approaches to management of technological efficiency of created technical objects are considered. The expediency of use of wide aspect of the decision of the specified problem is shown. Work on creation of a control system is presented in the form of three consecutive stages.

Ключевые слова: технический объект, технологический процесс, технологическая эффективность, система автоматического управления.

Задачу управления технологической эффективностью $\left(\mathrm{E}_{\mathrm{T}}\right)$ технических объектов (ТО) следует рассматривать в двух аспектах, определяющих характер исходной позиции для решения рассматриваемой задачи:

- в узком аспекте, когда необходимо управлять $\mathrm{E}_{\mathrm{T}}$ существующего ТО,

- в широком аспекте, когда необходимо управлять $\mathrm{E}_{\mathrm{T}}$ еще не существующего, а только создаваемого ТО.

Характер исходной позиции определяет подход и пути решения задачи управления $\mathrm{E}_{\mathrm{T}} \mathrm{TO}$.

Если поставлена задача в узком аспекте, то есть задача управления $\mathrm{E}_{\mathrm{T}}$ существующего ТО, то ее решение сводится к разработке системы автоматического управления (САУ) технологическим процессом в нем. Заданный ТО обладает определенными, заданными (заложенными в него) технологическими свойствами. Разрабатываемая САУ должна обеспечить поддержание их на возможно более высоком уровне в процессе функционирования ТО. Речь идет об оперативном управляющем воздействии на ТО, на процесс реализации его технологических свойств в той или иной степени, в зависимости от условий функционирования ТО и возможностей САУ. Подобная задача носит традиционный характер.

Рассмотрим особенности управления создаваемым ТО (то есть, задачи в широком аспекте).

Задача управления $\mathrm{E}_{\mathrm{T}}$ еще не существующим, а лишь создаваемым ТО, существенно сложнее. Теперь ее решение состоит из двух частей,- накопительной и расходной:

- Первая часть решения задачи, накопительная, содержит стратегический этап и тактический этап управления технологическими свойствами создаваемого ТО (Рис.).

Стратегический этап состоит в анализе и выборе из известных (или создаваемых), наиболее целесообразных, лучшей технологии ТО.

Тактический этап состоит в анализе и выборе из известных (или создаваемых) наиболее целесообразных конструкций, действующих по выбранной технологии, лучшей конструкции ТО применительно к заданным условиям предстоящего его использования.

В стратегическом и в тактическом этапах решения задачи закладывают технологические свойства создаваемого ТО (Рис.) [1].

- Вторая часть решения задачи, расходная, содержит оперативный этап, который состоит в оперативном управляющем воздействии на создаваемый ТО, на предстоящий процесс реализации его технологических свойств в той или иной степени, в зависимости от условий функционирования ТО.

На оперативном этапе разрабатывают структуру САУ, разрабатывают ее алгоритм, систему технической диагностики состояния объекта и др. Оперативный этап растягивается на период расходования ТО своего ресурса работоспособности.

Естественно, решение задачи управления в широком аспекте позволяет создать ТО и САУ технологическим процессом в нем, обеспечивающие наиболее высокий уровень $\mathrm{E}_{\mathrm{T}} \mathrm{TO}$.

Значительный самостоятельный интерес представляет задача выбора лучшей технологии и лучшей конструкции TO, о которых сказано выше.

При выборе приходится анализировать составляющие $\mathrm{E}_{\mathrm{T}}$ : экологическую эффективность $\mathrm{E}_{\text {л }}$ экономическую эффективность $\mathrm{E}_{\mathrm{H}}$ и общетехническую эффективность $\mathrm{E}_{\mathrm{o}} \mathrm{TO}$. У реального ТО, как у нового, так и у работающего, уровень каждой из них разный 
Возникает вопрос о том, как по трем влияющим факторам оценить количественно уровень Е ТО. Сложность задачи очевидна. Ее решают традиционно следующим образом: в качестве учитываемых свойств создаваемого ТО выбирают единичную (агрегатную) производительность, надежность и экономичность.

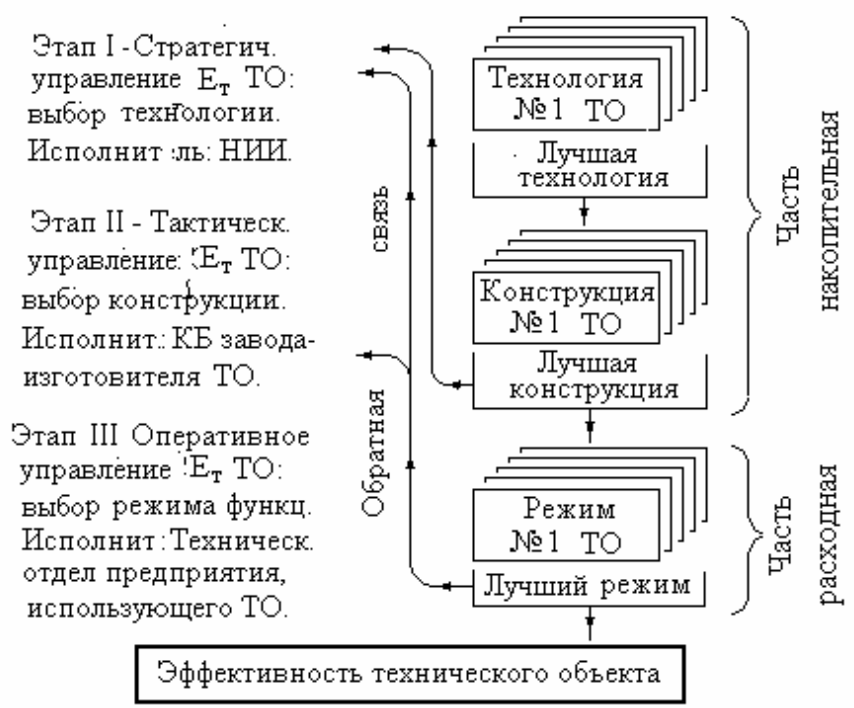

Pис. 1 - Структуно-погическа моделе формирования технопогической эффектености ТО

Изготовленные однотипные (серийные) ТО, обладающие выбранными свойствами, поступают различным потребителям. Условия использования серийных объектов у потребителей разные, поэтому уровень $\mathrm{E}_{\mathrm{T}} \mathrm{y}$ каждого объекта оказывается своим, особенным, отличным от других.

Поэтому вторую часть задачи управления каждым из этих ТО следует решать индивидуально: применительно к индивидуальным их свойствам, уровням $\mathrm{E}_{\mathrm{T}}$, уровням ее составляющих.

Сложность и громоздкость управления группой подобных серийных объектов, пребывающих в разных условиях эксплуатации, очевидна. Возможность создания типовой унифицированной САУ для агрегатов, находящихся в разных условиях эксплуатации, практически мало вероятна.

Для повышения эффективности изготовленных серийных ТО, целесообразно разделить их на группы с одинаковыми, характерными условиями использования.

Целесообразным решением первой задачи представляется целесообразным следующий подход, теоретически оправданный. Комплекс свойств ТО представляет собой многоуровневую пирамиду, в вершине которой находится свойство, именуемое технологической эффективностью. На втором уровне пирамиды находятся его составляющие свойства: $\mathrm{E}_{л}, \mathrm{E}_{\mathrm{H}}, \mathrm{E}_{\mathrm{o}}$. Каждая из них, в свою очередь, представляет собой набор составляющих свойств третьего уровня. Большинство из них, в свою очередь, составлены из групп свойств четвертого уровня пирамиды.

При формировании каждой из составляющих $\mathrm{E}_{\mathrm{T}}$ необходимо из набора ее свойств (элементов) четвертого или третьего уровня выбрать важнейшее - ведущее -свойство. В итоге, выбранные три ведущих свойства в совокупности образуют (составляют) $\mathrm{E}_{\mathrm{T}}$ создаваемого ТО - располагаются на вершине пирамиды:

$$
E_{\mathrm{T}}=\mathrm{f}\left(\mathrm{E}_{\mathrm{J}}, \mathrm{E}_{\mathrm{H}}, \mathrm{E}_{\mathrm{o}}\right) \text {. }
$$

Следует отметить важность и особое значение экологической эффективности в комплексе из трех составляющих эффективности ТО. Как известно, к настоящему периоду степень вредного антропогенного воздействия на природную среду достигла критического значения. Задача прямого управления $\mathrm{E}_{л} \mathrm{TO}$ во всех отраслях производства выросла в важную научно-техническую и организационно-техническую проблему, требующую неотложного решения [2 - 5].

При выборе ведущих свойств ТО необходимо соблюдать ряд условий:

- выбранное ведущее свойство должно быть наиболее существенным из числа рассмотренных,

- его уровень должен быть высоким, удовлетворяющим поставленным требованиям,

- закономерность изменения во времени выбранного свойства (вследствие износа объекта) должна быть известна,

- скорость снижения уровня проявления объектом ведущего свойства должна быть приемлемой,

- текущий уровень (численное значение) ведущего свойства должен поддаваться оперативному контролю системой технической диагностики (состояния ТО).

Следует отметить сложность учета динамики процесса износа ТО и отражения этого процесса на его свойствах, в том числе на ведущих свойствах, формирующих Е . Для получения необходимых конкретных данных, необходимо развивать научно-исследовательские изыскания в сфере предмета технической геронтологии [6, 7].

В результате выполнения первой части изложенной выше задачи удается сформировать $\mathrm{E}_{\mathrm{T}}$ в виде набора необходимых ведущих свойств, отражающих качественные и количественные свойства и уровень Е создаваемого ТО. Эти свойства в совокупности отражают, характеризуют исходный уровень Е созданного, изготовленного ТО. 
Располагая материалом, содержащим развернутые исходные данные о $\mathrm{E}_{\mathrm{T}}$ ТО и ее составляющих, можно приступить к осуществлению расходной части решения задачи - оперативному, третьему, этапу управления Е

Анализ структуры оборудования пищевой промышленности и его состояния свидетельствует о необходимости осуществления широкой программы его обновления, как полного, так и частичного: модернизации, реконструкции, технического перевооружения. Возникающие задачи требуют соответствующей разработки вопросов обновления средств автоматизации указанного оборудования. Обновление технологического оборудования и систем управления их технологическим процессом открывает возможности управления технологической эффективностью ТО, производственных участков, предприятий и составляющих отрасли в целом [8].

В нынешних условиях обеспечение высокого качества управления сложными ТО возможно при условии применения современных высокоинтеллектуальных компьютерно-интегрированных систем управления. При этом, разработка проблемы управления технологической эффективностью создаваемых технических объектов в широком аспекте должна носить системный характер, когда выдвигаемые требования технологов, конструкторов и автоматчиков к создаваемому объекту согласованы и гармонизированы $[9,10]$.

\section{Выводы:}

1. Задача управления $\mathrm{E}_{\mathrm{T}}$ создаваемого ТО состоит из двух частей, первая задача носит стратегический и тактический характер, вторая - оперативный характер.

2. Стратегическая и тактическая задачи состоят в выборе ведущих экологического, экономического и общетехнического свойств создаваемого объекта и формировании с их помощью исходного уровня его Е

3. Разработав материал, отражающий $\mathrm{E}_{\mathrm{T}}$ создаваемого ТО, можно приступить к решению второй, оперативной, задачи - созданию системы автоматического управления этим объектом.

4. Важной вспомогательной задачей является развитие в каждой отрасли производства научноисследовательских изысканий, посвященных изучению процесса износа ТО, особенно изучению динамики этого процесса.

\section{Литература}

1. Воінова С.О. Можливості управління ефективністю технічних об'єктів/ Труды 15-й Междунар. н.-т. конф. «Физические и компьютерные технологии», Харьков, 2-3 декабря 2009 г.- Харьков: ХНПК «ФЭД», 2009. С. 393 - 395.

2. Воінова С.О. Деякі особливості задачі управління екологічною ефективністю технічних об'єктів/ Труды 15-й Междунар. н. - т. конф. “Физические и компьютерные технологии”, Харьков, 2 - 3 декабря 2009р.- Харьков: ХНПК «ФЭД», 2009.- С. 395 - 398

3. Воінова С.О. Екологічна культура - важливий елемент професійної культури фахівція/ Тези доповідей учасників 16 Міжнар. конф. $з$ автоматичного управління “Автоматика-2009” (22 - 25 вер. 2009, Чернівці)Чернівці: Книги-ХXI, 2009.- С. 414 - 415

4. Воинова С.А. Управление техническими объектами как задача экологического характера/ III Всеукраинская научно-практ. конф. «Информ. технологии и автоматизация - 2010» (14-15 окт. 2010, г. Одеса). Сб-к докладов.- Одесса: ОНАПТ, 2010.- С. 19.

5. Воінова С.О. Про актуальність управління екологічною ефективністю технічних об’ єктів/ «Енергетика та електрифікація», №1, 2012.- С. 64 - 67.

6. Воинова С.А. Техническая геронтология. Потенциал влияния на эффективность функционирования технических объектов/ Матер. за VI Международна научна практична конференция «Найновите постижения на европейската наука-2010», 17 - 25 юни, 2010г. Том 20 «Технологии. Физическа култура и спорт».- София: «Бял ГРАД-БГ» ООД, 2010.- С. 79 - 84.

7. Воінова С.О. Управління технічними об’єктами і технічна геронтологія/ Щоквартальний наук.-виробн. журнал «Автоматизація технологічних і бізнес-процесів», 2011, № 7, 8.- Одеса: ОНАХТ, 2011.- С. 20 - 23.

8. Воінова С.О. Оновлення технічного об'єкта як засіб управління його технологічною ефективністю/ Щоквартальний наук.-виробн. журнал «Автоматизація технологічних і бізнес-процесів», 2011, № 5, 6.Одеса: ОНАХТ, 2011.- С. 25 - 27.

9. Воінова С.О. Системний підхід до управління технологічною ефективністю технічних об' єктів/ Физические и компьютерные технологии.- Труды 17-й Международной научно-технической конференции, 20 - 21 сентября 2011г.- Харьков: ХНПК «ФЭД», 2011.- С.105 - 108.

10. Воинова С.А. О системности подхода к управлению эффективностью технических объектов/ IV Всеукраинская научно-практ. конф. «Информ. технологии и автоматизация - 2011» (12 - 14 окт. 2011 , г. Одеса). Сб-к докладов. Одесса: ОНАПТ, 2011.- С. 5 - 6. 